\title{
Tetracyclines as Inhibitors of Pre-microRNA Maturation: A Disconnection between RNA Binding and Inhibition
}

\author{
Amanda L. Garner, ${ }^{*},+\ddagger$ Daniel A. Lorenz, ${ }^{\dagger, \perp}$ Jorge Sandoval, $^{\ddagger, \perp}$ Erin E. Gallagher, ${ }^{\dagger}$ Samuel A. Kerk, $^{\dagger}$ \\ Tanpreet Kaur, ${ }^{\dagger}$ and Arya Menon ${ }^{\dagger}$ \\ ${ }^{\dagger}$ Department of Medicinal Chemistry, College of Pharmacy, and ${ }^{\ddagger}$ Program in Chemical Biology, University of Michigan, Ann Arbor, \\ Michigan 48109, United States
}

Supporting Information

\begin{abstract}
In a high-throughput screening campaign, we recently discovered the rRNA-binding tetracyclines, methacycline and meclocycline, as inhibitors of Dicer-mediated processing of microRNAs. Herein, we describe our biophysical and biochemical characterization of these compounds. Interestingly, although direct, albeit weak, binding to the premicroRNA hairpins was observed, the inhibitory activity of these compounds was not due to RNA binding. Through additional biochemical and chemical studies, we revealed that metal chelation likely plays a principle role in their mechanism of inhibition. By exploring the activity of other known RNA-binding scaffolds, we identified additional disconnections between direct RNA interaction and inhibition of Dicer processing. Thus, the results presented within provide a valuable case study in the complexities of targeting RNA with small molecules, particularly with weak binding and potentially promiscuous scaffolds.
\end{abstract}

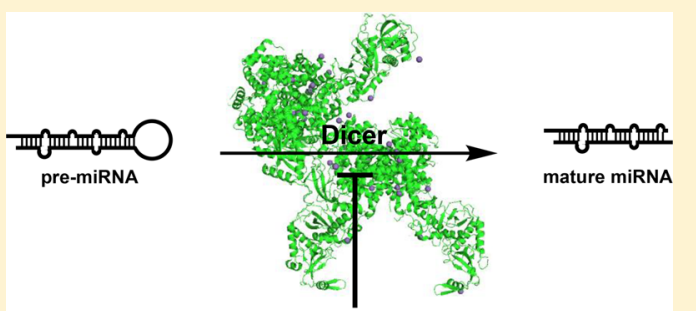

KEYWORDS: MicroRNA, Dicer, high-throughput screening, tetracyclines

RNA-targeted probe and drug discovery have become important areas of chemical biology and medicinal chemistry research. ${ }^{1,2}$ From the promise of personalized medicine to the hugely significant, yet largely understudied role of RNA in human biology and disease, targeting RNA with small molecules has emerged as a sought-after approach in biomedical research. While the complexities of RNA, particularly its net electronegative charge and high degree of structural plasticity, coupled with a lack of high-resolution structural information, ${ }^{3}$ have historically made such efforts difficult; a rarely discussed challenge associated with targeting RNA are the often-discovered disconnections between RNA binding and inhibition of biological function.

MicroRNAs (miRNAs or miRs) are a family of small noncoding RNAs that play critical roles in the fine-tuning of gene expression. ${ }^{4}$ Dicer-mediated processing of pre-microRNAs (pre-miRNA or pre-miR) is the penultimate step of miRNA maturation, which occurs prior to loading of the mature miRNA into the RNA-induced silencing complex (RISC). ${ }^{5}$ As many miRNAs become aberrantly regulated in disease, ${ }^{6-8}$ we became interested in developing a strategy by which to discover small molecule modulators of this process, with the goal of identifying those that could do so in a RNAselective manner. Using our catalytic enzyme-linked click chemistry assay (cat-ELCCA) for Dicer, ${ }^{9-11}$ we performed a high-throughput screen (HTS) targeting pre-miR-21, ${ }^{12}$ an oncogenic miRNA overexpressed in the majority of human tumors, ${ }^{13}$ and a target of interest in the field. ${ }^{14-27}$ Herein, we disclose the hits from our prior $\mathrm{HTS}^{12}$ and reveal tetracyclines as the only RNA-binding hits from our small molecule screen. Interestingly, through additional studies, we have revealed that RNA binding is not required for this activity, highlighting the necessity for careful analysis when characterizing inhibitors of RNA biology.

As reported previously, our screening campaign using commercial small molecule libraries resulted in very few hit compounds with demonstrated selectivity for pre-miR-21 over pre-let-7d, which was used in our counterscreen. ${ }^{12}$ To determine if this apparent selectivity was due to RNA binding properties, six compounds that showed modest, yet specific inhibition of pre-miR-21 processing were purchased and analyzed (Figure 1A). Methacycline and meclocycline, members of the tetracycline family of antibiotics, ${ }^{28,29}$ which were also identified from the screen and showed nonspecific inhibition of Dicer processing, were also examined (Figure 1A).

Direct binding to pre-miR-21 and pre-let-7d was measured via surface plasmon resonance spectroscopy (SPR) using biotinylated pre-miRs immobilized to streptavidin chips. From this analysis, only methacycline and meclocycline were found to exhibit affinity for the pre-miRNA hairpins. Measured $K_{\mathrm{d}}$ values for methacycline were 9.9 and $17 \mu \mathrm{M}$, and those for

Received: March 6, 2019

Accepted: April 22, 2019

Published: April 22, 2019 
A

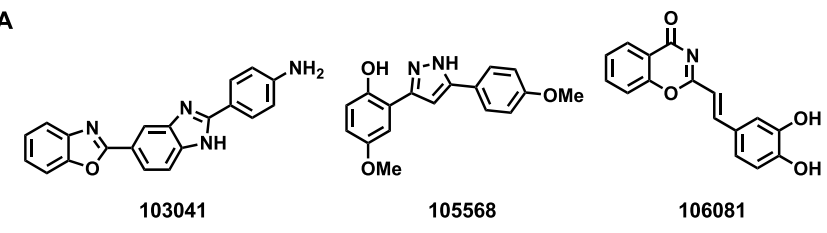

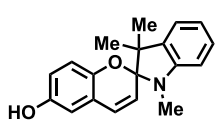

244289

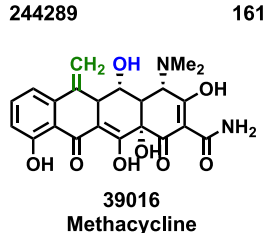

16141

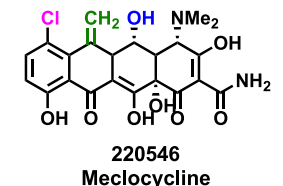

B

\begin{tabular}{ccc}
\hline CCG ID & $I_{50}(\mu \mathrm{M})($ pre-miR-21) & $I_{50}(\mu \mathrm{M})$ (pre-let-7d) \\
\hline 103041 & 229 & $\mathrm{NI}$ \\
105568 & 148 & $\mathrm{NI}$ \\
106081 & 692 & $\mathrm{NI}$ \\
244289 & 15 & $\mathrm{NI}$ \\
16141 & 645 & $\mathrm{NI}$ \\
122706 & 398 & $\mathrm{NI}$ \\
39016 & 56 & 97 \\
220456 & 62 & 80
\end{tabular}

Figure 1. HTS results. (A) Structures of hit compounds from the primary screen that showed selectivity for pre-miR-21 and identified tetracyclines, methacycline, and meclocycline. (B) Table of measured $\mathrm{IC}_{50}$ values $(\mathrm{NI}=$ no inhibition $)$.

meclocycline were 2.1 and $5.8 \mu \mathrm{M}$, for pre-miR-21 and pre-let$7 \mathrm{~d}$, respectively (sensorgrams can be found in Figure S1; Figure 2B), which are similar to the reported affinities for ribosomal RNA (rRNA). ${ }^{29}$ The $\mathrm{IC}_{50}$ values for these compounds from fresh powders were subsequently measured

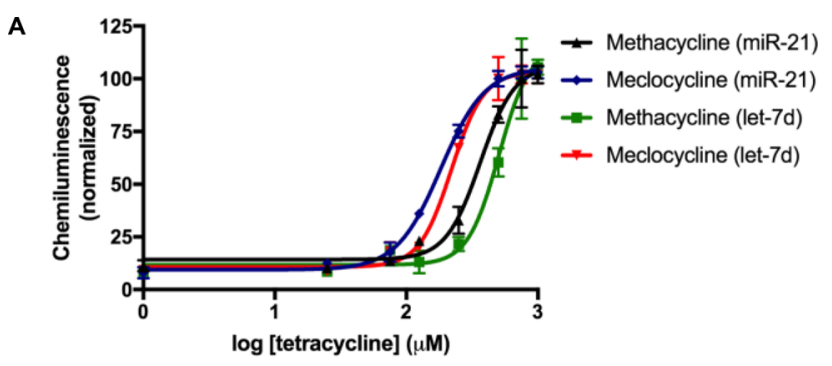

B

\begin{tabular}{lcccc}
\hline & \multicolumn{2}{c}{ pre-miR-21 } & \multicolumn{2}{c}{ pre-let-7d } \\
\hline Tetracycline & $\mathrm{K}_{\mathrm{d}}(\mu \mathrm{M})$ & $\mathrm{IC}_{50}(\mu \mathrm{M})$ & $\mathrm{K}_{\mathrm{d}}(\mu \mathrm{M})$ & $\mathrm{IC}_{50}(\mu \mathrm{M})$ \\
\hline Methacycline & $9.9 \pm 0.4$ & $314-437$ & $17 \pm 0.3$ & $432-749$ \\
Meclocycline & $2.1 \pm 0.1$ & $170-196$ & $5.8 \pm 0.1$ & $201-240$
\end{tabular}

Figure 2. Inhibition of Dicer processing using freshly dissolved methacycline and meclocycline. (A) Dose-dependent inhibition as measured via cat-ELCCA. (B) Table of binding affinities and inhibition constants. $\mathrm{IC}_{50}$ values are represented as $95 \%$ confidence intervals. as 383 and $189 \mu \mathrm{M}$ against pre-miR-21 and 800 and $225 \mu \mathrm{M}$ against pre-let-7d (Figure 2). We attribute the observed differences in potency from our HTS results (Figure $1 \mathrm{~B})^{12}$ to tetracycline instability during long-term storage in DMSO (see below) ${ }^{30}$ In sum, these results indicate that the identification of low molecular weight small molecules that target RNA hairpins is difficult, likely due to a bias in the chemical space of these collections toward protein binders.

The tetracyclines are natural product antibiotics that inhibit bacterial translation by binding to $16 \mathrm{~S}$ rRNA and blocking amino acyl-tRNA delivery. ${ }^{31}$ However, this class of molecules has been linked to a number of other RNA- and protein-related biological processes, including inhibition of the mitochondrial $^{32}$ and human ${ }^{33}$ ribosomes, promotion of SMN2 splicing, ${ }^{34}$ and inhibition of matrix metalloproteinases. ${ }^{35}$ To determine if this scaffold generally inhibits Dicer processing of pre-miRNAs, we screened a collection of tetracyclines (Figure 3).

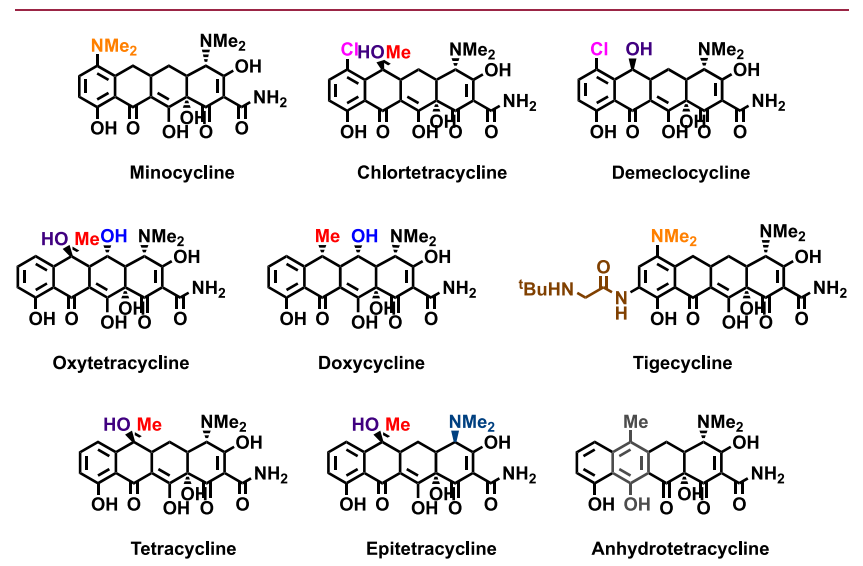

Figure 3. Structures of select tetracyclines analyzed in cat-ELCCA.

As shown in Figure 4A, inhibition ranged from $40-100 \%$ after testing at a single concentration of $1.0 \mathrm{mM}$. We then profiled the dose-responsive inhibition of select tetracyclines, and $\mathrm{IC}_{50}$ values were measured as $194-558 \mu \mathrm{M}$ against premiR-21 and 265-664 $\mu \mathrm{M}$ against pre-let-7d (Figures 4B-D). From these analyses, it was noted that the presence of a chlorine substituent, as found in meclocycline and chlortetracycline, was important for potent inhibition of Dicermediated maturation, and 2-4-fold improvements were observed for each over the parent scaffolds of methacycline and tetracycline, respectively (Figures 2 and 4B-D). Additionally, upon analysis of the two most common tetracycline degradation products, epitetracycline and anhydrotetracycline (Figure 3$),{ }^{36}$ we found that the anhydro product boosted the inhibitory activity of the tetracycline scaffold (Figure 4A). Thus, this or other degradation products could have contributed to our conflicting results between the HTS stocks and fresh powders. It is important to note that although tetracyclines are not potent inhibitors of pre-miRNA maturation by Dicer, inhibition of this process has historically been a challenge due to the complexity of the Dicer enzyme and its interaction with a pre-miRNA. ${ }^{37}$ In fact, even RNAbinding proteins, ${ }^{38,39}$ RNA aptamers, $^{40}$ and peptides ${ }^{18,26}$ that are known to inhibit Dicer processing in cells, exhibit high $\mathrm{IC}_{50}$ values relative to their binding affinities in in vitro assays. Because of the poor catalytic properties of Dicer in vitro, our assay uses excess enzyme to ensure sufficient signal-to- 


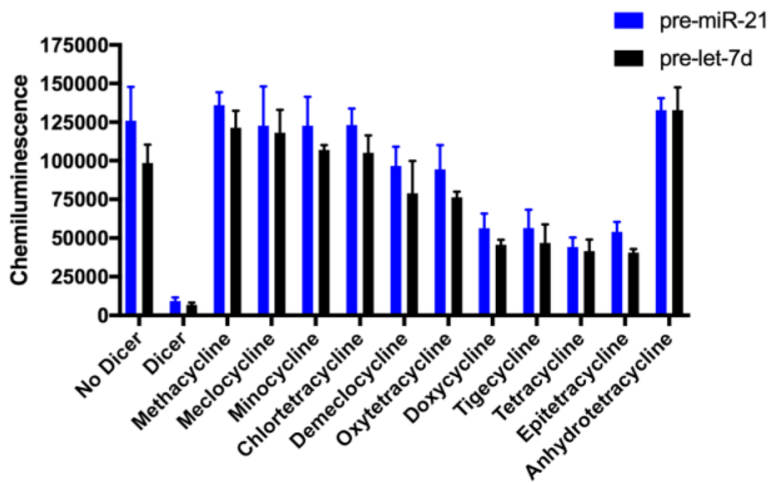

B

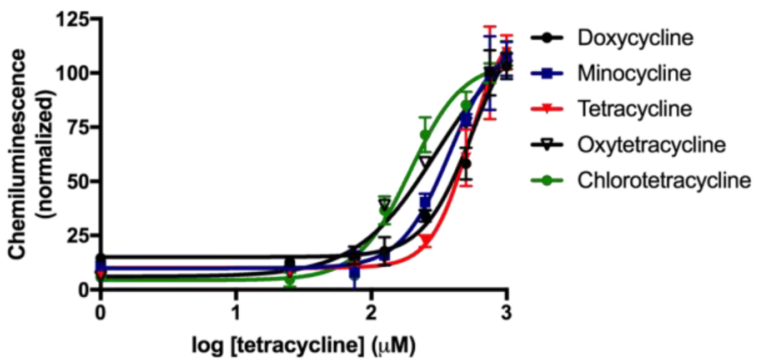

C

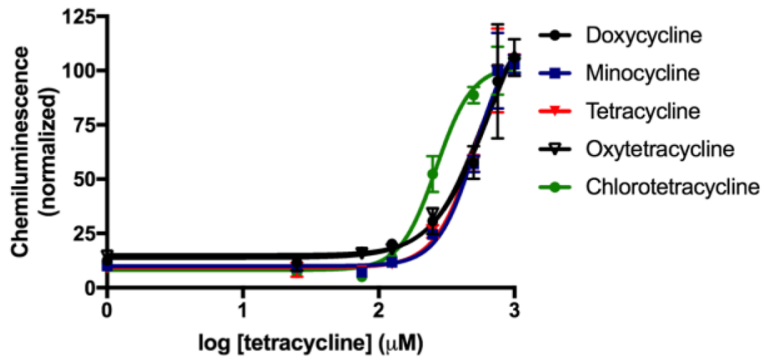

D

\begin{tabular}{ccc}
\hline Tetracycline & $\mathrm{IC}_{50}(\mu \mathrm{M})($ pre-miR-21) & $\mathrm{IC}_{50}(\mu \mathrm{M})(\mathrm{pre}-\mathrm{let}-7 \mathrm{~d})$ \\
\hline Doxycycline & $433-1410$ & $433-1299$ \\
Minocycline & $305-539$ & $437-744$ \\
Tetracycline & $434-1005$ & $421-865$ \\
Oxytetracycline & $200-918$ & $431-1015$ \\
Chlortetracycline & $155-274$ & $237-307$
\end{tabular}

Figure 4. Tetracyclines as inhibitors of Dicer-mediated pre-miRNA maturation. (A) Tetracycline library screening at $1.0 \mathrm{mM}$. (B,C) Plot of dose-dependent inhibition by select tetracyclines against pre-miR21 and pre-let-7d processing, respectively, in cat-ELCCA. (D) Table of $\mathrm{IC}_{50}$ values represented as $95 \%$ confidence intervals.

background for accurate and reproducible detection; and thus, antagonism of processing with a nonoptimized small molecule is a challenge.

Prior to our work, other researchers have investigated the tetracyclines as inhibitors of Dicer-mediated pre-miRNA maturation; ${ }^{41,42}$ however, conflicting results were reported. Using a fluorescent intercalator displacement (FID) assay, Herdewijn and co-workers observed no inhibition with select family members. ${ }^{41}$ This finding is not surprising, as tetracyclines are not known to participate in this type of interaction with nucleic acids. Similar to our results, but using a FRET assay, Duca and colleagues observed inhibition in the presence of doxycycline, oxytetracycline, and minocycline, with $\mathrm{IC}_{50}$ values of $129-380 \mu \mathrm{M}^{42}$ While RNA binding was hypothesized to play a significant role in the mechanism-ofaction, ${ }^{42}$ this was not definitively proven. To probe this possibility, we utilized the chemically modified tetracycline (CMT) derivative, CMT-3, which lacks antibacterial properties and was designed as a metalloproteinase inhibitor. ${ }^{43,44}$ Although this compound has been recently shown to bind to human $80 \mathrm{~S}$ ribosome, ${ }^{33}$ because it lacks the dimethylamino group (Figures $5 \mathrm{~A}$ ), we suspected that its general RNA binding

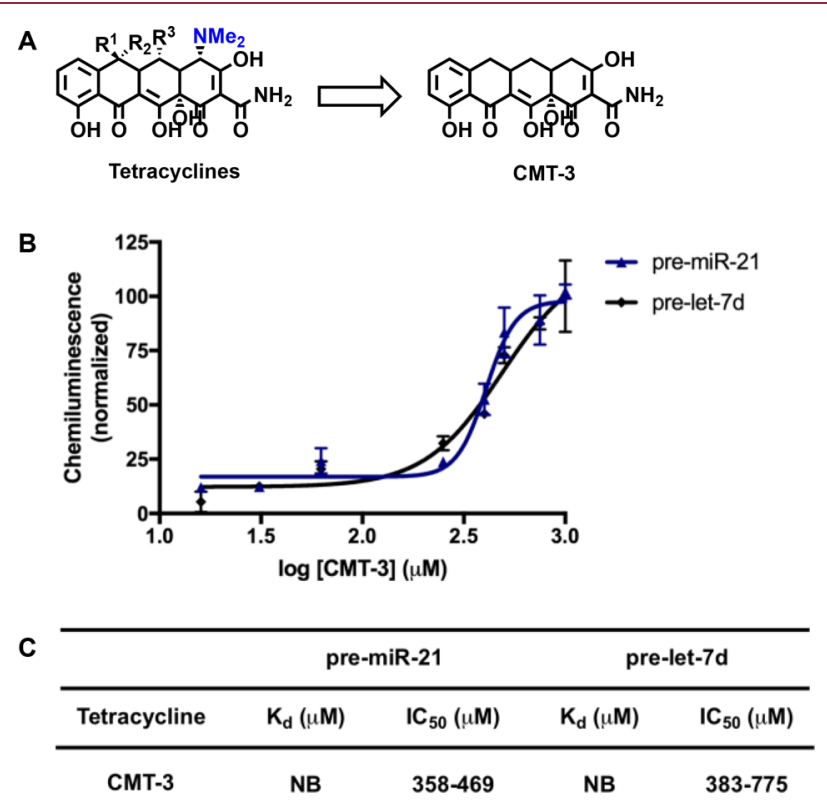

Figure 5. CMT-3. (A) Structure of CMT-3 in comparison to the tetracycline scaffold. (B) Plot of dose-dependent inhibition by CMT3. (C) Table of binding affinities and inhibition constants $(\mathrm{NB}=$ no binding). The $\mathrm{IC}_{50}$ values are represented as $95 \%$ confidence intervals.

affinity would be weakened due to its absence of a basic amine. Indeed, we observed no binding of CMT-3 to either pre-miR21 or pre-let-7d via SPR (sensorgrams can be found in Figure $\mathrm{S} 2$ ). Despite this, inhibition, with measured $\mathrm{IC}_{50}$ values very similar to that of methacycline (Figures 2 and 5B,C), was observed, indicating that RNA binding is likely not important for the mechanism of inhibition by the tetracyclines.

Aside from rRNA binding, another important activity of the tetracyclines is their ability to coordinate metal ions. ${ }^{35}$ In fact, the pharmacological actions of the tetracyclines are dependent upon metal complexes, most notably with $\mathrm{Ca}^{2+}$ and $\mathrm{Mg}^{2+} \cdot 35$ Because Dicer is a $\mathrm{Mg}^{2+}$-dependent RNase III enzyme, ${ }^{45}$ we first investigated whether the tetracyclines were scavenging this metal ion from the buffer, thereby preventing formation of an active Dicer enzyme. Even in the presence of lower or higher concentrations of $\mathrm{MgCl}_{2}(1-3 \mathrm{mM})$, methacycline was still able to inhibit Dicer activity (Figure S3A,B). Thus, these results demonstrate that the tetracyclines are not sequestering $\mathrm{Mg}^{2+}$. As many studies have found that $\mathrm{Mg}^{2+}$ and $\mathrm{Ca}^{2+}$ can form differential complexes with the tetracyclines, ${ }^{35,46}$ we next examined the effect of $\mathrm{Ca}^{2+}$ on methacycline inhibition. While testing in the presence of excess $\mathrm{CaCl}_{2}\left(2: 1 \mathrm{CaCl}_{2} / \mathrm{MgCl}_{2}\right)$ was impossible due to the abolishment of Dicer function, ${ }^{47,48}$ Dicer activity and inhibition by methacycline in a 1:1 mixture of $\mathrm{CaCl}_{2}$ and $\mathrm{MgCl}_{2}$ was retained potentially indicating that both metal complexes are active (Figure S3C,D). Based on the inconclusive nature of these results, we prepared an acetyl protected tetracycline (Figure 6A) to more thoroughly probe the requirement of metal binding for tetracycline inhibitory activity. Using this analogue, Dicer inhibition was weakened 


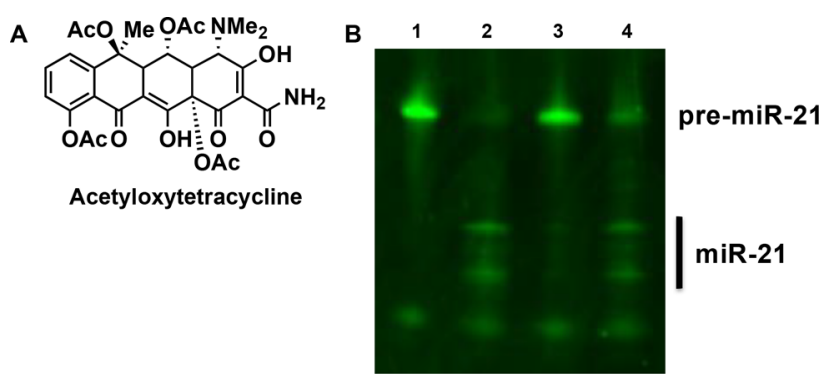

Figure 6. Acetyl-protected oxytetracycline. (A) Structure. (B) Inhibitory activity in an in-solution Dicer assay. Lane $1=$ pre-miR$21(500 \mathrm{nM})$; Lane 2 = pre-miR-21 + Dicer; Lane 3 = pre-miR-21 + Dicer and oxytetracycline $(1.0 \mathrm{mM})$; Lane $4=$ pre-miR-21 + Dicer and the aceylated oxytetracycline $(1.0 \mathrm{mM})$. Two miRNA bands are observed due to the use of a modified pre-miR-21 substrate containing a $5^{\prime}$ biotin connected to the RNA via a PEG linker. ${ }^{10}$

(Figures 6B), providing some evidence for the role of metal chelation in tetracycline activity, although hydrogen-bonding interactions could also be disrupted with this analogue. Of note, this is not the first instance of a metal chelating group showing inhibition of Dicer. ${ }^{25}$

Human Dicer contains multiple domains outside of its double-stranded RNA-binding domain (dsRBD) and RNase III domains to ensure proper miRNA processing; however, $E$. coli RNase III functions as a homodimer with only RNase III and dsRBD subunits. ${ }^{45}$ Thus, to determine which of Dicer's domains may be the target of the tetracyclines, we tested the activity of methacycline against this homologue. As shown in Figure S4, this enzyme was inhibited by the tetracycline, indicating that the RNase III and dsRBD domains may be the target of these molecules. As the large size of Dicer $(200 \mathrm{kDa})$ and its domains $(>100 \mathrm{kDa})$, which also function as homodimers, ${ }^{49}$ preclude direct binding studies, future efforts will focus on employing structural biology strategies to decipher the mechanism-of-action of the tetracyclines in inhibiting human Dicer activity. However, because we consistently observed lower $\mathrm{IC}_{50}$ values for pre-miR-21 over pre-let-7d, we are excited about the possibility that the tetracyclines may be functionally inactivating the catalytic activity of the RNase III domains. Previous studies have found that the terminal loop region of a pre-miRNA controls the kinetics of Dicer processing, where hairpins of larger loop size (e.g., pre-let-7) are matured more rapidly than those with smaller loop sizes (e.g., pre-miR-21). ${ }^{50,51}$ Thus, using this model, inhibition of pre-miR-21 should be observed at lower concentrations due to its slower rate of processing, particularly for weakly potent inhibitors like the tetracyclines. Future explorations in this area will be reported in due course.

Finally, because tetracyclines are members of known RNAtargeted chemical space, we were eager to investigate how their activity compared to other well-established RNA-binding small molecules. ${ }^{3}$ The aminoglycoside antibiotics, streptomycin, kanamycin, and neomycin, and groove-binding bis-benzimidazole, Hoechst 33258 (Figure $7 \mathrm{~A}$ ), were examined at a single concentration using cat-ELCCA. Interestingly, despite the fact that these molecules displayed nanomolar binding affinity for both pre-miRNAs ( $K_{\mathrm{d}}$ values of $100-700 \mathrm{nM}$; sensorgrams can be found in Figure S5), no inhibition of Dicer maturation was observed (Figure 7B). Thus, we hypothesize that these molecules either do not bind to the competitive Dicer cleavage site or do not induce a structural change in the hairpin

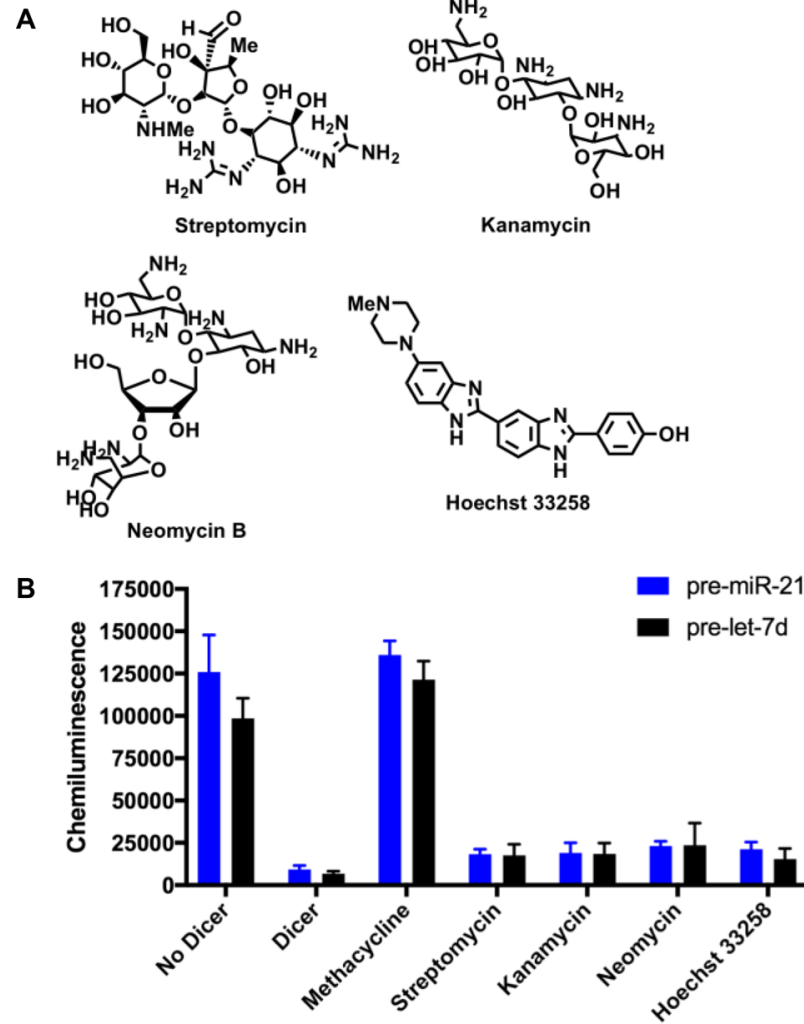

Figure 7. Comparison of the inhibitory activity of methacycline and other known RNA binders $(1.0 \mathrm{mM})$ against Dicer-mediated processing of pre-miR-21 and pre-let-7d. (A) Structures. (B) Activity in cat-ELCCA.

structure by which to inhibit Dicer processing. These results, however, should provide caution to those researchers engaged in using binding only assays for targeting RNA with small molecules, and highlight the need for functional assays immediately downstream of such approaches, particularly prior to medicinal chemistry optimization of potency and specificity.

In conclusion, we have characterized tetracycline-based antibiotics as inhibitors of Dicer-mediated pre-miRNA processing. Unexpectedly, despite their ability to directly bind to the RNA hairpins, the inhibitory activity of these compounds was not due to RNA binding capacity. By comparing tetracyclines to other members of known RNAtargeted chemical space, we discovered additional discrepancies between RNA binding and functional inhibitory properties. These combined findings highlight the complexity of targeting RNA with small molecules and the need for thorough characterization, both biochemical and biophysical, of such compounds to provide detailed mechanisms-of-action, particularly with weak binding ligands or potentially promiscuous scaffolds. Although our hit tetracyclines, methacycline and meclocycline, were not active in a cellular miRNA activity assay (Figure S6), further synthetic derivatizations could be carried out to improve activity. ${ }^{52}$ As tetracyclines have been recently shown to target human rRNA, $^{33}$ which is much more abundant than miRNAs in a cell, comprising 80$85 \%$ and $\ll 1 \%$ of total cellular RNA, respectively, ${ }^{53}$ this may provide an explanation for this observation. Accordingly, the biological activities of the tetracyclines are likely not due to inhibition of miRNA maturation. Such optimized compounds 
could be useful probes to interrogate the basic biology of Dicer and its implications in human disease, ${ }^{54,55}$ in addition to aiding structural biology studies of human Dicer.

\section{ASSOCIATED CONTENT}

\section{S Supporting Information}

The Supporting Information is available free of charge on the ACS Publications website at DOI: 10.1021/acsmedchemlett.9b00091.

General materials and methods, assay protocols, synthetic methods, supplementary figures, NMR, and purity spectra (PDF)

\section{AUTHOR INFORMATION}

\section{Corresponding Author}

*E-mail: algarner@umich.edu.

\section{ORCID $\odot$}

\section{Amanda L. Garner: 0000-0002-0870-3347}

\section{Author Contributions}

${ }^{\perp}$ These authors contributed equally. The manuscript was written through contributions of D.A.L. and A.L.G. All authors have given approval to the final version of the manuscript.

\section{Funding}

This work was supported by a pilot grant from the University of Michigan Center for the Discovery of New Medicines and the NIH (R01 GM118329 to A.L.G., T32 GM008597 to J.S., and T32 GM007767 to E.E.G.).

\section{Notes}

The authors declare no competing financial interest.

\section{ABBREVIATIONS}

miRNA or miR, microRNA; HTS, high-throughput screening; cat-ELCCA, catalytic enzyme-linked click chemistry assay

\section{REFERENCES}

(1) Garner, A. L. RNA Therapeutics. Top. Med. Chem. 2018, DOI: 10.1007/978-3-319-68091-0.

(2) Connelly, C. M.; Moon, M. H.; Schneekloth, J. S., Jr. The emerging role of RNA as a therapeutic target for small molecules. Cell Chem. Biol. 2016, 23, 1077-1090.

(3) Thomas, J. R.; Hergenrother, P. J. Targeting RNA with small molecules. Chem. Rev. 2008, 108, 1171-1224.

(4) Vidigal, J. A.; Ventura, A. The biological functions of miRNAs: lessons from in vivo studies. Trends Cell Biol. 2015, 25, 137-147.

(5) Ha, M.; Kim, V. N. Regulation of microRNA biogenesis. Nat. Rev. Mol. Cell Biol. 2014, 15, 509-524.

(6) Li, Z.; Rana, T. M. Therapeutic targeting of microRNAs: current status and future challenges. Nat. Rev. Drug Discovery 2014, 13, 622638.

(7) Rupaimoole, R.; Slack, F. J. MicroRNA therapeutics: towards a new era for the management of cancer and other diseases. Nat. Rev. Drug Discovery 2017, 16, 203-221.

(8) Lorenz, D. A.; Garner, A. L. Approaches for the discovery of small molecule ligands targeting microRNAs. Top. Med. Chem. 2017, 27, 79-110.

(9) Lorenz, D. A.; Song, J. M.; Garner, A. L. High-throughput platform assay technology for the discovery of pre-microRNAselective small molecule probes. Bioconjugate Chem. 2015, 26, 19-23.

(10) Lorenz, D. A.; Garner, A. L. A click chemistry-based microRNA maturation assay optimized for high-throughput screening. Chem. Commun. 2016, 52, 8267-8270.

(11) Garner, A. L. cat-ELCCA: catalyzing drug discovery through click chemistry. Chem. Commun. 2018, 54, 6531-6539.
(12) Lorenz, D. A.; Vander Roest, S.; Larsen, M. J.; Garner, A. L. Development and implementation of an HTS-compatible assay for the discovery of selective small-molecule ligands for pre-microRNAs. SLAS Disc. 2018, 23, 47-54.

(13) Selcuklu, S. D.; Donoghue, M. T. A.; Spillane, C. miR-21 as a key regulator of oncogenic processes. Biochem. Soc. Trans. 2009, 37, 918-925.

(14) Gumireddy, K.; Young, D. D.; Xiong, X.; Hogenesch, J. B.; Huang, Q.; Deiters, A. Small-molecule inhibitors of microRNA miR21 function. Angew. Chem., Int. Ed. 2008, 47, 7482-7484.

(15) Naro, Y.; Thomas, M.; Stephens, M. D.; Connelly, C. M.; Deiters, A. Aryl amide small-molecule inhibitors of microRNA miR-21 function. Bioorg. Med. Chem. Lett. 2015, 25, 4793-4796.

(16) Naro, Y.; Ankenbruck, N.; Thomas, M.; Tivon, Y.; Connelly, C. M.; Gardner, L.; Deiters, A. Small molecule inhibition of microRNA miR-21 rescues chemosensitivity of renal-cell carcinoma to topotecan. J. Med. Chem. 2018, 61, 5900-5909.

(17) Chirayil, S.; Chirayil, R.; Luebke, K. J. Discovering ligands for a microRNA precursor with peptoid microarrays. Nucleic Acids Res. 2009, 37, 5486-5497.

(18) Diaz, J. P.; Chirayil, R.; Chirayil, S.; Tom, M.; Head, K. J.; Luebke, K. J. Association of a peptoid ligand with the apical loop of pri-miR-21 inhibits cleavage by Drosha. RNA 2014, 20, 528-539.

(19) Bose, D.; Nahar, S.; Rai, M. K.; Ray, A.; Chakraborty, K.; Maiti, S. Selective inhibition of miR-21 by phage display screened peptide. Nucleic Acids Res. 2010, 43, 4342-4352.

(20) Bose, D.; Jayaraj, G.; Suryawanshi, H.; Agarwala, P.; Pore, S. K.; Banerjee, R.; Maiti, S. The tuberculosis drug streptomycin as a potential cancer therapeutic: inhibition of miR-21 function by directly targeting its precursor. Angew. Chem., Int. Ed. 2012, 51, 1019-1023.

(21) Ghosh, A.; Degyatoreva, N.; Kukielski, C.; Story, S.; Bhaduri, S.; Maiti, K.; Nahar, S.; Ray, A.; Arya, D. P.; Maiti, S. Targeting miRNA by tunable small molecule binders: peptidic aminosugar mediated interference in miR-21 biogenesis reverts epithelial to mesenchymal transition. MedChem Comm 2018, 9, 1147-1154.

(22) Shi, Z.; Zhang, J.; Qian, X.; Han, L.; Zhang, K.; Chen, L.; Liu, J.; Ren, Y.; Yang, M.; Zhang, A.; Pu, P.; Kang, C. AC1MMYR2, an inhibitor of Dicer-mediated biogenesis of oncomir miR-21, reverses epithelial-mesenchymal transition and suppresses tumor growth and progression. Cancer Res. 2013, 73, 5519-5531.

(23) Jiang, C.-S.; Wang, X.-M.; Zhang, S.-Q.; Meng, L.-S.; Zhu, W.H.; Xu, J.; Lu, S.-M. Discovery of 4-benzoylamino-N-(prop-2-yn-1yl)benzamides as novel microRNA-21 inhibitors. Bioorg. Med. Chem. 2015, 23, 6510-6519.

(24) Connelly, C. M.; Boer, R. E.; Moon, M. H.; Gareiss, P.; Schneekloth, J. S., Jr. Discovery of inhibitors of microRNA-21 processing using small molecule microarrays. ACS Chem. Biol. 2017, $12,435-443$.

(25) Yan, H.; Bhattarai, U.; Guo, Z.-F.; Liang, F.-S. Regulating miRNA-21 biogenesis by bifunctional small molecules. J. Am. Chem. Soc. 2017, 139, 4987-4990.

(26) Shortridge, M. D.; Walker, M. J.; Pavelitz, T.; Chen, Y.; Yang, W.; Varani, G. A macrocyclic peptide ligand binds the oncogenic microRNA-21 precursor and suppresses Dicer processing. ACS Chem. Biol. 2017, 12, 1611-1620.

(27) Velagapudi, S. P.; Costales, M. G.; Vummidi, B. R.; Nakai, Y.; Angelbello, A. J.; Tran, T.; Haniff, H. S.; Matsumoto, Y.; Wang, Z. F.; Chatterjee, A. K.; Childs-Disney, J. L.; Disney, M. D. Approved anticancer drugs target oncogenic non-coding RNAs. Cell Chem. Biol. 2018, 25, 1086-1094.

(28) Brodersen, D. E.; Clemons, W. M.; Carter, A. P.; MorganWarren, R. J.; Wimberly, B. T.; Ramakrishnan, V. The structural basis for the action of the antibiotics tetracycline, pactamycin, and hygromycin B on the 30 S ribosomal subunit. Cell 2000, 103, $1143-1154$

(29) Chukwudi, C. U. rRNA binding sites and the molecular mechanisms of action of the tetracyclines. Antimicrob. Agents Chemother. 2016, 60, 4433-4441. 
(30) Palmer, A. C.; Angelino, E.; Kishony, R. Chemical decay of an antibiotic inverts selection for resistance. Nat. Chem. Biol. 2010, 6, 105-107.

(31) Wilson, D. N. Ribosome-targeting antibiotics and mechanisms of bacterial resistance. Nat. Rev. Microbiol. 2014, 12, 35-48.

(32) Hong, S.; Harris, K. A.; Fanning, K. D.; Sarachan, K. L.; Frohlich, K. M.; Agris, P. F. Evidence that antibiotics bind to human mitochondrial ribosomal RNA has implications for aminoglycoside toxicity. J. Biol. Chem. 2015, 290, 19273-19286.

(33) Mortison, J. D.; Schenone, M.; Myers, J. A.; Zhang, Z.; Chen, L.; Ciarlo, C.; Comer, E.; Natchiar, S. K.; Carr, S. A.; Klaholz, B. P.; Myers, A. G. Tetracyclines modify translation by targeting key human rRNA substructures. Cell Chem. Biol. 2018, 25, 1506-1518.

(34) Hastings, M. L.; Berniac, J.; Liu, Y. H.; Abato, P.; Jodelka, F. M.; Barthel, L.; Kumar, S.; Dudley, C.; Nelson, M.; Larson, K.; Edmonds, J.; Bowser, T.; Draper, M.; Higgins, P.; Krainer, A. R. Tetracyclines that promote SMN2 exon 7 splicing as therapeutics for spinal muscular atrophy. Sci. Transl. Med. 2009, 1, 5ra12.

(35) Guerra, W.; Silva-Caldeira, P. P.; Terenzi, H.; Pereira-Maia, E. C. Impact of metal coordination on the antibiotic and non-antibiotic activities of tetracycline-based drugs. Coord. Chem. Rev. 2016, 327$328,188-199$.

(36) Sokoloski, T. D.; Mitscher, L. A.; Yuen, P. H.; Juvarkar, J. V.; Hoener, B. Rate and proposed mechanism of anhydrotetracycline epimerization in acid solution. J. Pharm. Sci. 1977, 66, 1159-1165.

(37) Liu, Z.; Wang, J.; Cheng, H.; Ke, X.; Sun, L.; Zhang, Q. C.; Wang, H.-W. Cryo-EM structure of human Dicer and its complexes with a pre-miRNA substrate. Cell 2018, 173, 1191-1203.

(38) Newman, M. A.; Thomson, J. M.; Hammond, S. M. Lin-28 interaction with the let-7 precursor loop mediates regulated microRNA processing. RNA 2008, 14, 1539-1549.

(39) Chen, Y.; Yang, F.; Zubovic, L.; Pavelitz, T.; Yang, W.; Godin, K.; Walker, M.; Zheng, S.; Macchi, P.; Varani, G. Targeted inhibition of oncogenic miR-21 maturation with designed RNA-binding proteins. Nat. Chem. Biol. 2016, 12, 717-723.

(40) Lunse, C. E.; Michlewski, G.; Hopp, C. S.; Rentmeister, A.; Caceres, J. F.; Famulok, M.; Mayer, G. An aptamer targeting the apical-loop domain modulates pri-miRNA processing. Angew. Chem., Int. Ed. 2010, 49, 4674-4677.

(41) Maiti, M.; Nauwelaerts, K.; Herdewijn, P. Pre-microRNA binding aminoglycosides and antitumor drugs as inhibitors of Dicer catalyzed microRNA processing. Bioorg. Med. Chem. Lett. 2012, 22, 1709-1711.

(42) Tran, T. P. A.; Vo, D. D.; Di Giorgio, A.; Duca, M. Ribosometargeting antibiotics as inhibitors of oncogenic microRNAs biogenesis: old scaffolds for new perspectives in RNA targeting. Bioorg. Med. Chem. 2015, 23, 5334-5344.

(43) Lokeshwar, B. L.; Escatel, E.; Zhu, B. Cytotoxic activity and inhibition of tumor cell invasion by derivatives of a chemically modified tetracycline CMT-3 (COL-3). Curr. Med. Chem. 2001, 8, 271-279.

(44) Golub, L. M.; McNamara, T. F.; D’Angelo, G. D.; Greenwald, R. A.; Ramamurthy, N. S. A non-antibacterial chemically-modified tetracycline inhibits mammalian collagenase activity. J. Dent. Res. 1987, 66, 1310-1314.

(45) Zhang, H.; Kolb, F. A.; Jaskiewicz, L.; Westhof, E.; Filipowicz, W. Single processing center models for human Dicer and bacterial RNase III. Cell 2004, 118, 57-68.

(46) Lambs, L.; Decock-Le Reverend, B.; Kozlowski, H.; Berthon, G. Metal ion-tetracycline interactions in biological fluids. 9. circular dichroism spectra of calcium and magnesium complexes with tetracycline, oxytetracycline, doxycycline and chlortetracycline and discussion of their binding modes. Inorg. Chem. 1988, 27, 3001-3012.

(47) Provost, P.; Dishart, D.; Doucet, J.; Frendewey, D.; Samuelsson, B.; Raedmark, O. Ribonuclease activity and RNA binding of recombinant human Dicer. EMBO J. 2002, 21, 5864-5874.

(48) Werner, A.; Skakun, V. V.; Ziegelmuller, P.; Hahn, U. A fluorescence correlation spectroscopy-based enzyme assay for human Dicer. Biol. Chem. 2012, 393, 187-193.
(49) Takeshita, D.; Zenno, S.; Lee, W. C.; Nagata, K.; Saigo, K.; Tanokura, M. Homodimeric structure and double-straded RNA cleavage activity of the C-terminal RNase III domain of human Dicer. J. Mol. Biol. 2007, 374, 106-120.

(50) Zhang, X.; Zeng, Y. The terminal loop region controls microRNA processing by Drosha and Dicer. Nucleic Acids Res. 2010, 38, 7689-7697.

(51) Feng, Y.; Zhang, X.; Graves, P.; Zeng, Y. A comprehensive analysis of precursor microRNA cleavage by human Dicer. RNA 2012, 18, 2083-2092.

(52) Liu, F.; Myers, A. G. Development of a platform for the discovery and practical synthesis of new tetracycline antibiotics. Curr. Opin. Chem. Biol. 2016, 32, 48-57.

(53) Jankowsky, E.; Harris, M. E. Specificity and non-specificity in RNA-protein interactions. Nat. Rev. Mol. Cell Biol. 2015, 16, 533544.

(54) Song, M.-S.; Rossi, J. J. Molecular mechanisms of Dicer: endonuclease and enzymatic activity. Biochem. J. 2017, 474, 16031618.

(55) Foulkes, W. D.; Priest, J. R.; Duchaine, T. F. DICER1: mutations, microRNAs and mechanisms. Nat. Rev. Cancer 2014, 14, $662-672$. 